\title{
Performance measurement in an input-output framework
}

\author{
Thijs ten Raa
}

Received: 5 March 2012 / Accepted: 17 April 2012 / Published online: 17 April 2012

(C) 2012 ten Raa; licensee Springer. This is an Open Access article distributed under the terms of the Creative Commons Attribution License (http://creativecommons.org/licenses/by/2.0), which permits unrestricted use, distribution, and reproduction in any medium, provided the original work is properly cited.

\begin{abstract}
This paper fruitfully combines two complementary theories: performance measurement and input-output analysis. Our point of departure is the theory of the consumer, who maximizes utility subject to a budget constraint. His well-being can be measured by the change in the consumption bundle, valued at constant prices. Inputoutput analysis is invoked to impute the change in this bundle to technical change, a terms-of-trade effect and two types of efficiency change. The analysis is extended to environmental economics.
\end{abstract}

Keywords performance measurement - growth accounting · terms of trade . environmental constraint

JEL Classification C67 · O47 · Q56

\section{Introduction}

In this paper I bring to fruition the neoclassical measurement of performance change in an input-output framework. Some pitfalls are avoided. First, market prices need not be perfectly competitive and, more generally, the observed allocation of resources may be inefficient. Solow's ascription of TFP-growth to technical change holds in an idyllic neoclassical world where resources are rewarded according to their marginal productivities, but not beyond. Market power, managerial slacks and other sources of inefficiency abound and we must factor in their variations to properly account for performance changes. Since these conditions differ between industries, an inputoutput framework seems promising.

$\mathrm{T}$ ten Raa $(\bowtie)$

Department of Economics, Tilburg University, 5000 LE Tilburg, The Netherlands

e-mail: tenraa@uvt.nl 
The strategy of this paper is the following. I find it reasonable to assume that households are price takers. This point of departure is quite powerful, because the first order condition of the problem of the consumer, which equates the marginal rates of substitution to the price ratios, reveal that prices measure marginal utilities (up to an uninteresting multiplicative constant, the marginal utility of money) even when those prices are distorted. So I measure changes in the level of well-being of consumers by tracking final consumption. Then I use input-output analysis to decompose that bill of final goods and services. It may increase due to reductions in input coefficients, Solow's technical change, but obviously for other reasons as well. This paper sorts it out.

\section{Utility based performance measurement}

In general equilibrium analysis - of which input-output is an important instance consumers have initial endowments, including their labor skills. Some consumers are better off than others, i.e. have bigger endowments, and this translates into greater budget sets, hence opportunities. If, however, we assume away income effects in their utility functions - as is the case for constant elasticity of substitution (including CobbDouglas and Leontief) utility functions, then the relationship between the percentage rate of change in utility and in consumption is independent of the level of well being.

Formally, a consumer maximizes $U(x)$ subject to $p x \leq p \omega$, where $x$ is a consumption vector, $\omega$ the initial endowment, $p$ the price (row) vector, and $U$ the utility function. I assume $U$ is linearly homogeneous (no income effects). Exogenous to the consumer are $p$ and $\omega$ (price taking behavior). How does the consumer respond to change? Well, that's determined by the envelope theorem, according to which the change in the objective value is given by the partial derivatives of the objective function with respect to the exogenous parameters. (The point of the theorem is that the change in the endogenous parameter, consumption, may be ignored.) Since the envelope theorem is formulated for free maximization problems, we must first handle the constraint. This is done in the usual way by setting up the Lagrangian function, $U(x)+\lambda(p \omega-p x)$, and maximizing that.

Change the parameters: $d p$ and $d \omega$. By the envelope theorem $d U$ is determined by the partial derivatives with respect $p$ and $\omega$. The first effect is $\lambda(\omega-x) d p$; the consumer is better of his resources are priced higher and worse off if his consumption bundle is priced higher. The second effect is $\lambda p d \omega$; the consumer is better off if he is better endowed. In total $d U=\lambda d p(\omega-x)+\lambda p d \omega$. This can be simplified. (For simplicity I assume, quite realistically, that the budget constraint is binding, but otherwise the simplification still holds by the phenomenon of complimentary slackness, $\lambda=0$.) Differentiating the budget equation, $p(\omega-x)=0$, we obtain $d p(\omega-x)+p d \omega-p d x=0$. Substituting, $d U=\lambda p d x$. The well-being of the consumer is assessed by tracking consumption. An immediate and well known consequence is that the vector of marginal utilities is $U^{\prime}=\lambda p$.

Here the Lagrange multiplier is the marginal utility of income, but the noincome effects assumption gets rid of it. Formally, linear homogeneity means $U(\theta x)=\theta U(x)$. Differentiating with respect to (positive) $\theta$, using the chain rule, 
$U^{\prime}(x) x=U(x)$. (This is Euler's theorem.) The (percentage) rate of change of utility becomes now $d U / U=\lambda p d x / U^{\prime}(x) x=\lambda p d x / \lambda p x=p d x / p x$. If we have two consumers, then their rates of change are $p d x^{1} / p x^{1}$ and $p d x^{2} / p x^{2}$. Defining $x$ as the total consumption bundle, the weighted average is $\left(p x^{1} / p x\right) p d x^{1} / p x^{1}+$ $\left(p x^{2} / p x\right) p d x^{2} / p x^{2}=p d x / p x$. In other words, $p d x / p x$ is a robust measure for tracking utility.

Performance, however, is the latter per unit of endowment, hence as a growth rate performance is measured by subtracting the change in endowment from the change in consumption: $(p d x-p d \omega) / p x$.

\section{Embedding performance measurement in the input-output framework}

I assume that utility is a function of the consumption of the produced commodities. This neglects the utility of leisure time, but is not bad if labor is supplied inelastically (e.g. when overall utility is a Cobb-Douglas function of commodity consumption utility and leisure). I also identify household consumption with domestic final demand, i.e. incorporating investment. This has been given a theoretical foundation by Weitzman (1976). Net output $y=x+z+s$, where $z$ is net exports and $s$ is slack (output not allocated to intermediate demand, domestic final demand or exports, i.e. inventory investment). The initial endowment does not enter this equation. I assume that the initial endowment consists of (currently) nonproduced factors, capital $K$ and labor $L$. This dichotomy between produced and nonproduced commodities is handled by reserving the last two dimensions for capital and labor, with prices $r$ and $w$. With a slight abuse of notation I reserve $p$ for the price (row) vector of the produced goods and services-the price vector of Section 2 becoming ( $p \quad w r)$. The performance measure becomes $(p d x-r d K-w d L) / p x$.

If there is no slack $(s=0)$ and balance of payments $(p z=0)$ then consumption $x$ may be replaced by net output $y$ in the performance measure and we recognize the Solow residual. I will not make these neoclassical assumptions. I will use, however, the balance equations, for gross output $q=A q+y$, and for the factor inputs $K=$ $k q+\kappa$ and $L=l q+\lambda$. Input-output coefficients populate matrix $A$ (intermediate inputs) and row vectors $k$ and $l$ (factor inputs). $\kappa$ and $\lambda$ represent idle capital and labor. (Product slack $s$ was already accounted for in net output $y$.) Substitution turns performance $(p d x-r d K-w d L) / p x$ into $[p d(q-A q-z-s)-r d(k q+\kappa)-$ $w d(l q+\lambda)] / p x$. Applying the product rule to $A q, k q$ and $l q$, and rearranging, the numerator of this performance measure is decomposed into four parts:

(i) $-(p d A+r d k+w d l) q$

(ii) $-p d z$

(iii) $(p-p A-r k-w l) d q$

(iv) $-(p d s+r d \kappa+w d \lambda)$

All have to be divided by $p x$. The first term measures the reductions in the input coefficients, i.e. technical change. Because we multiply with gross output components and divide by the main component of net output, this is a weighted average of industrial Solow residuals, with the weight summing to the gross/net output ratio 
of the economy (Domar aggregation, ten Raa 2006). The second term measures the value in the change in the net imports, $-z$, i.e. the terms-of-trade-effect. It is straightforward to understand this. If the balance of payments does not change, $p z$ constant, then $-p d z=(d p) z$, which measures the improvement in the prices of the net exports. The third term measures the reallocation of output in terms of profitability, i.e. allocative efficiency change. The fourth term measures the reduction of slack in the utilization of goods and services, capital and labor, i.e. X-efficiency change (Comanor and Leibenstein 1969).

A perfectly competitive economy shows only the first two effects, technical change and the terms-of-trade effect. Indeed, the trade sector can be considered an industry where the exports are the inputs and the imports are the outputs. An improvement in the terms of trade is a reduction of the exports required per unit of imports, just like a reduction of the input coefficients in the regular industries. Solow (1957) analyzed a closed perfectly competitive economy and discovered that the residual (now called Solow residual) measures technical change. The role of the term-of-trade has been in the air for long and was articulated by ten Raa and Mohnen (2002). They also relate the broad decomposition into technical change and efficiency change to the operations research/productivity literature. The further decomposition into X-efficiency and allocative efficiency has been studied in the same literature, but in micro contexts. This paper encompasses all, using an input-output framework of the economy.

I have not assumed that the prices are equilibrium prices. Even when prices are distorted, they point the way to the greatest increase of utility, by the first order condition of the problem of the consumer, and that's all we needed. Things get different when one wants to assess the level of efficiency. This is matter of determining how much better off the consumers could be. There are several ways to find the Pareto frontier. A natural one - particularly when assuming linearly homogeneous utility functions - is to find alternative allocations that maximize the utility levels with a common multiplicative factor, subject to the balances. Then the prices are the shadow prices to the latter constraints. This methodology is particularly helpful when markets are incomplete, prices are missing.

\section{The environmental extension}

The classical example of missing prices is that for externalities, such as pollution. Elsewhere I (2008) have argued that a conservative way to estimate the inefficiency involved is to assume Leontief preferences. I have also shown that, then, the problem to determine inefficiency is solved by maximizing the level of consumption subject to the balance constraints. Denote that level by $u$, where the observed level corresponds to $u=1$. Hence $u$ is the expansion factor for consumption. For example, if $u$ can be 1.25 , then consumption could be $25 \%$ higher and, therefore, it is only at $80 \%$ of its potential. We say that the economy is $20 \%$ inefficient. The constraints are $A q+x u+$ $z \leq q, k q \leq K, l q \leq L, p z \leq p z^{\circ}$. Here the variables are $q, u, z \cdot p z^{\circ}$ is the observed trade balance, at world prices. Maximizing $u$, the shadow prices to the produced balance constraint can be seen to be proportional to $p$ (ten Raa 2006). The shadow prices to the next two constraints are denoted $r$ and $w$. Bring in emission coefficients, 
organized in row vector $m$, and a policy level $M$ of maximum emission. That is equivalent to adding a constraint $m q \leq M$. Denote the shadow price by $t$, then the dual constraint becomes $p \leq p A+r k+w l+t m$, with slack indicating that the output of a product must be zero. These shadow prices are competitive prices, sustaining the efficient allocation, and reflect the cost of pollution, which is equal to the Pigovian tax.

Performance growth accounting à la Section 3 is straightforward, because formally pollution is equivalent to the addition of a third resource.

\section{Conclusion}

The reconciliation of performance measurement and input-output analysis is mutually beneficial. The input-output framework facilitates economy-wide performance measurement, including a quantification of the terms-of-trade effect and a decomposition of efficiency change in allocative and X-efficiency changes, even down to the level of industry. Conversely, performance measurement makes input-output analysis richer. The doctor not only knows how the parts of the body interact, but also how healthy the patient is.

\section{Competing interests}

The author declares that he has no competing interests.

\section{References}

Comanor WS, Leibenstein H (1969) Allocative efficiency, X-efficiency and the measurement of welfare losses. Economica 26:304-309

Solow R (1957) Technical change and the aggregate production function. Rev Econ Stat 39(3):312-320 ten Raa T (2006) The economics of input-output analysis. Cambridge University Press, Cambridge ten Raa T (2008) Debreu's coefficient of resource utilization, the Solow residual, and TFP: the Connection by Leontief Preferences. J Product Anal 30:191-199

ten Raa T, Mohnen P (2002) Neoclassical growth accounting and frontier analysis: a synthesis. J Product Anal 18(2):111-128

Weitzman ML (1976) On the welfare significance of national product in a dynamic economy. Q J Econ 90:156-162 